\title{
OX40L-expressing B cells promote SLE
}

OX40L
on B cells
supports
plasma cell
development
and [T follicular
helper] cell
maturation

OX40 ligand (OX40L) supports the development of $\mathrm{T}$ follicular helper $\left(\mathrm{T}_{\mathrm{FH}}\right)$ cells via its expression on B cells, according to new research. "We studied OX40L because the gene TNFSF4 (that encodes OX40L) is a risk gene for the development of systemic lupus erythematosus (SLE)," explains corresponding author Timothy Vyse. The results of this study shed light on the mechanisms by which high levels of OX40L predispose individuals to SLE.

To investigate the function of OX40L on T cells and B cells, the researchers developed three knockout mouse strains: OX40L germline knockout mice and mice lacking

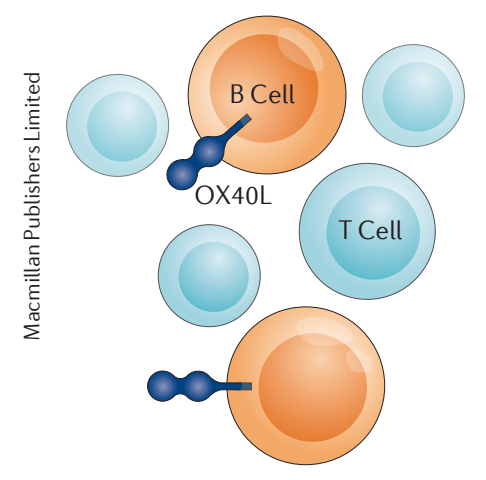

OX40L in either their $\mathrm{CD}^{+} \mathrm{T}$ cells or in their B cells. Following immunization with a $\mathrm{T}$ cell-dependent antigen, all three knockout strains had reduced primary humoral responses compared with control mice. However, mice with OX40L-deficient B cells also had impaired secondary humoral responses, unlike mice with OX40L-deficient CD4 ${ }^{+} \mathrm{T}$ cells, suggesting a distinct role for OX40L on B cells.

As OX40L has a well-established role in $\mathrm{T}$ cell activation, the researchers analysed the splenic T cell composition of these three mouse strains. As expected, immunized OX40Ldeficient mice had lower proportions of T effector cells than control mice; this defect was evident in all three knockout strains and could not explain the difference in secondary responses, indicating a role for $\mathrm{B}$ cell OX40L that is independent of $\mathrm{T}$ cell activation.

Following immunization, mice with OX40L-deficient B cells had lower percentages of plasma cells and fewer germinal centre $\mathrm{T}_{\mathrm{FH}}$ cells than control mice. By contrast, no differences were observed in mice with OX40L-deficient CD4 ${ }^{+} \mathrm{T}$ cells, indicating that OX40L on B cells supports plasma cell development and $\mathrm{T}_{\mathrm{FH}}$ cell maturation.

In two mouse models of SLE - a congenic model and a graft-versus-host model - OX40L deficiency ameliorated disease and was accompanied by a reduction in anti-dsDNA autoantibodies, kidney deposition of immunoglobulin and germinal centre $\mathrm{T}_{\mathrm{FH}}$ cell and plasma cell numbers. Similar findings were observed in the graft-versus-host model in mice with OX40L-deficient B cells, suggesting that OX40L predisposes to SLE via its expression on B cells. "These findings describe one mechanism by which excess OX40L activity promotes disease, namely B cell OX40L promotes $\mathrm{T}_{\mathrm{FH}}$ cell generation," concludes Vyse.

Jessica McHugh

ORIGINAL ARTICLE Cortini, A. et al. B cell

OX40L supports $T$ follicular helper cell development and contributes to SLE pathogenesis. Ann. Rheum. Dis. http://dx.doi. org/10.1136/annrheumdis-2017-211499 (2017) FURTHER READING Croft, M. \& Siegel, R.M. Beyond TNF: TNF superfamily cytokines as targets for the treatment of rheumatic diseases. Nat. Rev. Rheumatol. 13, 217-233 (2017) 